\title{
LO LITERARIO Y LA PERIODIZACIÓN LITERARIA
}

Francisco Abad

UNED

\section{Variedades de la lengua}

Los códigos lingüísticos, al igual que cualesquiera otros códigos, no tienen una existencia formal separada de los seres humanos que hacen uso de ellos; de la misma manera que por ejemplo una ley queda interpretada por el tribunal que la aplica, un código idiomático se halla asentado en hablantes y grupos de hablantes y ello da lugar a la variación interior en su estructura.

La lingüística norteamericana sistematizó hace ya años algo que por otra parte no resulta difícil observar, a saber; que las variaciones de la lengua son geográficas, sociales y de estilo (o, se dice también, de «registro»). Si hacemos una abstracción de toda lengua en cualquier momento dado, descubriremos en ella su diferenciación espacial, la sociolingüística, y la que deriva de los diversos estilos con que es usada (formal, familiar, académico, técnico...); Roman Jakobson lo ha recordado, y ha escrito cómo «la diversidad entre y dentro de las lenguas puede y debe 'estudiarse en tres dimensiones sincrónicas geográfica, social y estilística', en la formulación de Bright»! .

Efectivamente es un hecho empírico lo que se llama el carácter no monolítico de las lenguas humanas, su diferenciación y por ello su complejidad interior; de la misma manera

1.- R. Jakobson, Obras selectas, Madrid, Gredos, 1988, p. 228.

Tropelias, n.․ 1, 1990. 


\section{FRANCISCO ABAD}

la diversidad entre las lenguas posee la misma naturaleza geográfica, social y estilística: el análisis de una muestra del léxico románico tal como lo hizo Gerhard Rohlfs así lo manifiesta ${ }^{2}$.

Este triple eje según el cual se diversifica el idioma hace que se den en él variedades dialectales del mismo - dialecto andaluz, hablas canarias, etc.-, variedades sociolingüísticas ${ }^{3}$, y variedades de estilo: una de tales variedades es la literaria. Yo puedo expresarme en tono familiar e informal, o bien en una lengua más cuidada, etc, y si lo sé hacer, puedo asimismo expresarme literariamente. La variedad literaria de la lengua es uno de sus estilos expresivos, lo mismo que la variedad científico-técnica, la jurídica...; el hablar literario consiste en una de las diversificaciones propias de todo idioma, que posee igualmente distintas diversificaciones de estilo, y además geográficas y socioculturales.

La lengua es instrumento de comunicación o medio de expresión - podemos decir-, y por ello posee un carácter propiamente «instrumental»: se utiliza para diferentes finalidades, no es concebible sin ellas, y así es posible emplearla con "estilos» distintos según el motivo de manifestación del respeto o del afecto, de afirmación científica, ..., que nos mueva; uno de estos motivos es la voluntad literaria, y por ello se emplea con el intento de lograr un discurso poético.

«La autosuficiencia autárquica de un instrumento constituiría una contradicción en los términos», ha subrayado en el presente contexto de ideas Jakobson ${ }^{4}$, y en efecto el idioma tiene entre otras finalidades la del logro poético; el conjunto de sus finalidades hacen del mismo un instrumento interiormente complejo, con variabilidad interna.

Lo literario es una de las variedades de estilo con que puede ser usada la lengua, y además de esos estilos hemos dicho que el idioma presenta diferenciaciones geográficas y también diastráticas (sociolingüísticas). Hace ya unos años los estudios dialectales comprobaron el arcaísmo o la innovación que se daba en las hablas de hombres y de mujeres, según sus condiciones de vida; más tarde ha tomado cuerpo el análisis de los dialectos verticales en los núcleos urbanos, y se distinguen en ellos los diferentes grupos caracterizados de hablantes (que constituyen los «microcosmos» lingüísticos) y el habla urbana en su conjunto («macrocosmos» lingüístico). Etc. Como otra dimensión de estudio de la variabilidad y la variación en las lenguas y entre las lenguas se plantea el idioma artístico; la lengua literaria constituye una de las maneras de estilo en el empleo del instrumento comunicativo y expresivo.

\section{La literatura}

La esencia autónoma e intransitiva de lo artístico y por tanto de lo específicamente poético fue muy bien vista por Kant cuando concibió lo estético en tanto una finalidad sin fin. Entre nosotros interpretó y glosó al filósofo Manuel García Morente, y algunas líneas de su exposición transmiten con claridad esta concepción kantiana del arte (y por tanto de la literatura):

2.- «La diferenciación léxica de las lenguas románicas», ahora en su libro conjunto Estudios sobre el léxico románico, Madrid, Gredos, 1979, pp. 125 ss.

3.- Crr. Diego Catalán, El español. Origenes de su diversidad, Madrid, Paraninfo, 1989, passim.

4.- Op. cit., p. 230. 


\section{LO LITERARIO Y LA PERIODIZACIÓN LITERARIA}

La estética encuentra su principio - son las palabras de García Morenteen la finalidad, finalidad subjetiva, finalidad $\sin$ fin... Lo bello... place en la pura contemplación, sin intención segunda... Los juicios de gusto son sintéticos a priori. En efecto establecen una relación entre la representación y el estado sentimental del sujeto, por lo cual se les puede llamar sintéticos. Pero además el carácter de desinterés que los diferencia de los juicios sobre lo agradable, y sobre todo la pretensión a la universalidad, los caracteriza como a priori... La finalidad estética... la podemos llamar finalidad formal subjetiva porque excluye todo fin, no queda en ella más que la pura forma de la finalidad 5 .

La literatura - podemos decir por nuestra cuenta - es (en lo que tiene de específicamente estética) finalidad sin fin, intransitividad que vale por ella misma, opacidad o espesor de formas construidas; se trata de una pura forma de la finalidad tal como hemos visto, de forma inmanente y valiosa por sí misma. La emoción artística es un juicio en el que el predicado (el sentimiento del sujeto) se añade a la representación; en la representación no se halla la subjetividad del sujeto, sino que ésta añade ese sujeto o destinatario de la obra a tal representación, y se produce entonces el juicio sintético de gusto. Según proclamaba el propio Kant a la letra, «para decidir si algo es bello o no, referimos la representación... mediante la imaginación (unida quizá con el entendimiento) al sujeto y al sentimiento... del mismon ${ }^{6}$.

En los lustros iniciales de la centuria presente Karl Vossler se dio asimismo cuenta de cómo la serie artística constituye una tradición formal e intransitiva, e indicaba que las obras de arte son específicamente ensayos de resolución de problemas estéticos que se han planteado; tales obras consisten pues en una individualidad formal que las avalora. Los contenidos humanos de los discursos artísticos son —en los mejores logros- genéricos y universales, pero la forma de cada uno de esos discursos debe tender a una novedad y originalidad; lo poético específico reside en la forma original y novedosa de la finalidad estética ${ }^{7}$.

Esta finalidad estética de las formas del discurso poético se alcanza en parte mediante el empleo de la lengua, empleo que como bien se sabe tiende a utilizar todos los recursos que tolere el sistema; tal idea luego repetida la estampó hace ya muchos años el romanista de Munich: «Por obra de los pocos grandes poetas de una época (manifestó) se potencian, se abultan como en la caricatura artística y como concentrándose en un espejo de aumento, las numerosas y pequeñas tendencias ocultas de la lengua materna» 8 .

Por supuesto la dirección que de manera más sistemática elaboró un concepto inmanente de la serie literaria fue el formalismo ruso; en esa traza resultan bien conocidas las posturas de Jakobson, quien en 1952 diría: «La concepción del lenguaje poético como la lengua con una predominante función poética nos ayudará a la hora de entender la

5.- M. García Morente, «La estética de Kant», que ahora figura como «Prólogo del traductor» en Manuel Kant, Crítica del juicio, Madrid, Espasa-Calpe, 1977, pp. 15-64: pp. 35, 40, 42, 49.

6.- Crítica..., p. 101. Hicimos una abreviada exposición de la estética kantiana y de las glosas de su traductor y comentarista español en nuestra participación en el VIII Simposio de la Sociedad Española de Literatura General y Comparada (el día 17 de diciembre de 1990); quisimos así modestamente que no quedara desapercibido - como nos parece que ha ocurrido un tanto - el segundo centenario de la publicación de la Crítica del juicio.

7.- Karl Vossler, Filosofía del lenguaje, trad. esp., Buenos Aires, Losada, 1963 4 , pp. 23 ss.

8.- lbid., p. 58. 


\section{FRANCISCO ABAD}

lengua prosaica de cada día, en la que la jerarquía de las funciones es diferente, pero donde esta función poética existe» ${ }^{9}$. De manera análoga proclamará nuestro autor cuatro años más tarde: «La función poética no es la única función del arte verbal sino sólo su función dominante y determinante, mientras que en todas las demás actividades verbales actúa como constituyente subsidiario y accesorio. Esta función, al promover la palpabilidad de los signos, ahonda la dicotomía fundamental de signos y objetos» ${ }^{10}$.

No estamos seguros nosotros de que las cosas sean tal como las veía Roman Jakobson: el énfasis sobre el mensaje por sí solo no caracteriza e individualiza a lo literario, sino que hace falta además que tal énfasis se vea acompañado de un contenido complejo y sugestivo; la literatura es forma percibida en cuanto forma y a la vez contenido (bellamente) connotado por esa forma.

En las actividades verbales no artísticas puede darse énfasis sobre el mensaje pero ello no quiere decir que lleven en sí la función poética: la función poética o estética del lenguaje se cumple - creemos - cuando al relieve u opacidad del mensaje se suma un componente de contenido que sugiere y evoca, que emociona al igual que emocionan las formas de la lengua y del discurso.

No creemos - en una palabra- que lo estético del arte verbal resida en el solo relieve predominante del mensaje o discurso, sino que la emoción artística deriva unitariamente tanto de la insistencia sobre la forma misma como del horizonte de alusiones y connotaciones evocadas. La función poética consiste en el énfasis sobre el mensaje siempre que ese énfasis dé lugar a un sugestivo contenido connotado; cuando el contenido no surge connotativamente el énfasis en el discurso no pasa de resultar una trivialidad (por ejemplo en las consignas políticas, la publicidad, etc.).

Más de un autor ha dicho y más de una vez se ha dicho que explicar lo literario es explicar la lengua con que está escrito el discurso, pero lo artístico no creemos nosotros que se agote con la elocución; además de las formas elocutivas otras formas se hallan presentes en la obra: la ordenación en capítulos de una novela o en actos de un texto teatral, el «género» literario en tanto suma de rasgos específicos... Lo poético no es sólo lo lingüístico del texto, y se mutila la realidad literaria si no tenemos en cuenta el resto de componentes de la misma.

En este orden de ideas se mantiene además a veces cómo la literariedad reside en la forma de la expresión del discurso y no en su forma del contenido; por supuesto la forma de la expresión es la elocución bella que contribuye al todo de la obra poética, pero no menos la forma del contenido significa asimismo literariedad según hemos dicho: género literario, disposición del discurso, etc.

La poesía no es sólo lengua porque lo artístico es algo más que elocución; lo poético no puede reducirse a lo lingüístico ${ }^{11}$.

9.-Op. cit., p. 234

10.- Ibid., p. 371.

11.- Diremos que entre nosotros quien primero se hizo eco de los formalistas rusos fue Eugenio Asensio en su bello libro Poética y realidad en el cancionero peninsular de la Edad Media, Madrid, Gredos, $1970^{2}$. 


\section{LO LITERARIO Y LA PERIODIZACIÓN LITERARIA}

\section{Literatura y significación}

Decimos que no existe obra literaria sin contenido: no es posible construir un discurso en cualquier lengua que no tenga contenido, ya que las lenguas poseen significación; al igual que la ciencia lingüística, los estudios literarios no pueden dejar de lado la semántica, pues en ese caso se alejarán de la real consistencia empírica de su objeto.

No obstante, se plantea el problema de cuál es el modo de identificar los verdaderos contenidos de los discursos literarios, de sentar cuál es la manera de referirse a las significaciones que acaba denotando-connotando la obra artística. En la crítica española de estos años últimos dos han sido las opciones que se han propuesto: Antonio García Berrio piensa en las constantes antropológicas que lógicamente se han de encontrar en discursos ideados y escritos por hombres 12; Francisco Abad propone que los textos se analicen en su contexto histórico-social y en el marco de la historia del pensamiento y de las mentalidades ${ }^{13}$. Personalmente creemos en efecto que así como todo logro artístico posee una individualidad y especificidad formal y estética, posee del mismo modo una especificidad cultural e histórica que hace que no sea intercambiable con otro cualquiera; la historia del arte no se repite, y por eso el significado y el sentido de las obras literarias creemos que ha de buscarse en su particular contexto histórico, social e ideológico.

\section{Michel Le Guern propuso hace unos años esto:}

El caso más típico de connotación libre es el texto poético... Tal tipo de texto presenta en cierta manera algunos agujeros lógicos que cada lector debe llenar con elementos sacados de su imaginación, de su propia experiencia, de su cultura o de su conocimiento de la personalidad del poeta. Estos elementos forman parte de la connotación, puesto que no están inscritos en la estructura lógica del texto ${ }^{14}$.

No creemos nosotros que pueda hablarse de la libertad de las connotaciones: resulta un problema planteado y que el buen estudioso debe intentar resolver (en la medida en la que en el conocimiento humano se pueden resolver las cosas), el del exacto sentido histórico-cultural de cada discurso estético. Interpretar una obra literaria - como quiere Le Guern - a partir de la propia experiencia o la propia imaginación lleva a la arbitrariedad y al vacío empírico: es como si el historiador interpretase la documentación de archivo según sus connotaciones imaginativas, o como si lo mismo hiciese el biólogo en el laboralorio.

Richard Ohmann por su parte sabido es que ha definido la obra literaria en tanto «un discurso... que carece de fuerza ilocutiva» ${ }^{15}$, y tampoco creemos nosotros que pueda afirmarse esto sin más; carecerá de fuerza ilocutiva el mero ejercicio de estilo, la página escrita sin buscar otra cosa que un logro artístico, pero salvo estos casos el discurso literario sí tiene un grado de fuerza ilocutiva, mayor en Unamuno y menor en algunos textos de Azorín por ejemplo, pero fuerza ilocutiva siempre. Gracián, Jovellanos, Pío Baroja, etc., fueron muy conscientes de lo que escribían ${ }^{16}$.

12.- Cfr. A. García Berrio, La construcción imaginaria en "Cántico» de Jorge Guillén, Limoges, TRAMES, 1985.

13.- F. Abad, Literatura e historia de las mentalidades, Madrid, Cátedra, 1987.

14.- M. Le Guern, La metáfora y la metonimia, trad, esp., Madrid, Cátedra, 1985, pp. 24-25.

15.- "Los actos de habla y la definición de la literatura», traducido en la compilación Pragmática de la comunicación literaria, Madrid, Arco/Libros, 1987, pp. 11 ss.: p. 28.

16.- Cfr. Francisco Abad, «Discusión de ideas en pragmática de la comunicación literaria», Actas del III Simposio Internacional de la AES, Madrid, UNED, 1990, I, pp. 61 ss. 


\section{FRANCISCO ABAD}

Nuestro punto de vista es muy distinto pues del que ha mantenido Ramón Trujillo, quien afirma:

La crítica literaria... es una ciencia... donde nunca se puede considerar un resultado sino como una interpretación más, tan verdadera como todas las otras posibles... Una interpretación no puede ser verdadera ni falsa, sino mejor o peor... Los resultados no dependen del método, sino de la inteligencia del crítico... Darle referentes al texto artístico es ir contra su propia esencia, que es fundamentalmente antirreferencial 17 .

Nos vemos obligados a no coincidir con tan respetado amigo, pero no entendemos cómo un estudioso preocupado por las cuestiones semánticas mantiene que el discurso literario es antirreferencial, y que su interpretación depende sólo de la habilidad del crítico; nuestra propuesta es que todo discurso trazado en cualquier lengua no puede dejar de tener significación dado que la lengua con la que está construido la tiene, y que el análisis ha de esforzarse en buscar el sentido empíricamente comprobable que en su circunstancia histórica posee ese discurso. Como decía Lucien Febvre, «también un poema, ... un drama son para nosotros documentos, testimonios de una historia viva y humana saturados de pensamiento y de acción en potencia», o sea, saturados de fuerza ilocutiva y con fuerza perlocutiva en potencia ${ }^{18}$.

\section{La lengua como diasistema}

Decíamos antes que la variedad literaria de la lengua es una de las variedades de estilo con que se habla, y que además de la diferenciación estilística los actos locutorios poseen otras dos, la geográfica y la sociocultural. Pensando en la variabilidad idiomática inducida socialmente y haciéndose eco sin duda de Roman Jakobson, Manuel Alvar ha escrito: «En esos sistemas inestables que son la lengua y la sociedad actuarán simultáneamente las fuerzas que llevan a la integración y al desmembramiento. Tal es el problema con que se encara el estructuralismo...: la revisión de la hipótesis monolítica del lenguaje» ${ }^{19}$.

En efecto la ciencia del lenguaje no puede considerar su objeto como algo uniforme y estático, porque no lo es: las variabilidades espaciales, diastráticas y de estilo que presenta $\mathrm{cl}$ idioma lo hacen consistir $\mathrm{cn}$ un objcto complcjo $\mathrm{c}$ interiormente diferenciado. La litcraria es una variedad estilística de la lengua lo mismo que el estilo académico de hablar, el humorístico, el familiar, etc.; en una lengua se comprehenden todas estas variaciones.

Al percibir estos hechos, el propio Manuel Alvar ha dicho también que «si dialecto es un suprasistema o un sistema de sistemas, el habla de una comunidad lo es» asimismo ${ }^{20}$; efectivamente todas las variaciones inducidas por lo social o lo geográfico, y las debidas

17.- R. Trujillo, «Algunas observaciones sobre el lenguaje poético», Anuario de Letras, XXIV, 1986, pp. 27-45: pp. 31-32 y 41 .

18.- La preciosa referencia de Febvre en sus Combates por la historia, trad. cast. parcial, Barcelona, Ariel, 1970, pp. 29-30.

19.- M. Alvar, Niveles socio-culturales en el habla de Las Palmas de Gran Canaria, Cabildo Insular de Gran Canaria, 1972, p. 214.

20.- Ibid., p. 231. Comp. del mismo autor «Lengua y dialecto. Delimitaciones históricas y estructurales», Arbor, 299, 1970, pp. 145-158. 


\section{LO LITERARIO Y LA PERIODIZACIÓN LITERARIA}

al estilo con que el hablante se exprese, integran la lengua de que se trate, que por ello no es un sistema monolítico ni distribuido de manera uniforme en la comunidad, sino un diasistema de procedimientos coexistentes, un suprasistema o "sistema de sistemas» (Jakobson) ${ }^{21}$.

\section{II}

\section{Algunas ideas sobre la periodización literaria}

La historia literaria se articula según una periodización determinada; efectivamente la serie artística (en este caso artístico-verbal) aparece establecida de acuerdo con realizaciones y valores distintos, diversificados, estimables por sí mismos ${ }^{22}$. No nos hallamos como en el caso de lo biológico ante una «evolución» o "progreso», pues los géneros, movimientos, obras..., constituyen realizaciones y realidades valiosas por sí mismas en su diversidad, y no tienden a un «tipo» mejor o a un resultado final de mayor complejidad y perfección. Picasso no «supera» ni hace prescindible a Velázquez; por lo mismo contamos tanto con Clarín como con Lope, y lo posterior no excluye a lo más antiguo.

Así la historia artística (literaria) se hace distinta a la de la ciencia, en la que técnicamente lo anterior no importa; sólo se estudian -por ejemplo- los conocimientos actuales en torno a la estructura del átomo o la más compleja cibernética, sin que sea necesario conocer los primeros ingenios mecánicos de tracción. Lo biológico evoluciona, digamos, según una ley de complejidad, y la ciencia acumulativamente; la historia del arte (en nuestro caso del arte verbal) atesora y guarda las obras de los distintos períodos. Nos encontramos pues con que la historia literaria no es un continuo ascendente, sino una sucesión internamente articulada de géneros, estilos, obras...

Creemos que al abordar la periodización literaria debe hacerse uso de dos criterios o principios de método que nos hagan resultar adecuados con los hechos ${ }^{23}$. Por una parte hay que atender a la complejidad de lo real histórico y no mutilarla, es decir, debemos hacernos cargo del total de componentes de la serie poética (hechos intrínsecos y específicos, pero también el marco global en que ocurren); de otro lado debe respetarse escrupulosamente esta especificidad de lo artístico, su consistencia formal e intransitiva.

Fn la contribución que hace a una obra de conjunto, Sentidos y usos del término estructura en las ciencias del hombre, Lucien Goldmann se ha referido con lucidez a dos hechos sucesivos perfectamente aplicables a los textos literarios. En primer término el de la "necesidad" de cada uno de sus aspectos o componentes dentro del conjunto formal y significativo que constituyen: «Para comprender el sentido de un autor - dice, citando a Pascal - hay que conciliar todos los pasajes contradictorios... Todo autor tiene un sentido en el que se concilian todos los pasajes contradictorios o carece en absoluto de sentido» ${ }^{24}$. No se trata sólo (desde luego) del contenido; materia y forma de la obra poética constituyen una configuración coherente y - por tanto- «necesaria».

22.- Empleamos la palabra «valor» tanto en el sentido corriente como en uno aproximado al que tiene en la lingüística de Saussure: forma diferencial y distinguida.

23.- Una opción teórica no se justifica porque esté vigente, sino por su adecuación a (la realidad empírica de) los hechos. No puede así - por ejemplo - denostarse a Guillaume antes de Chomsky, y luego justificarlo al amparo del mentalismo generativista.

24.- «El concepto de estructura significativa en Historia de la cultura», Sentidos y usos..., trad. cast., Buenos Aires, Paidós, 1971, pp. 105-113: p. 106. 


\section{FRANCISCO ABAD}

Pero además esta configuración es referible a una estructura sociocultural determinada; las obras tienen sentido como producto de una época histórico-cultural concreta. Las visiones del mundo que en ellas se encuentran no son sino componentes de la "situación» de las sociedades en el curso de la historia.

Goldmann concluye su trabajo con un balance de lógica investigadora de las ciencias humanas que en esencia es así:

- El concepto de «estructura (significativa)» constituye el principal instrumento de comprensión de los hechos humanos.

- Las obras artístico-verbales coinciden en su sentido con (derivan su sentido de) estructuras significativas (coherentes) o visiones del mundo.

- La Historia literaria sólo superará el nivel de la reflexión inteligente (ingeniosa) si opera con conceptos estructurales-significativos.

- Una tipología de las visioncs del mundo constituiría un inaprcciable instrumento del trabajo investigador ${ }^{25}$.

Tenemos pues con Lucien Goldmann que mediante la periodización rigurosa y ajustada el estudioso no busca sólo un expediente práctico con el que ordenar el material, sino un principio historiográfico garante de comprehensividad. Criterio de esta periodización ha de ser la atención a la complejidad de factores y concausas concurrentes en lo histórico ${ }^{26}$.

Junto al presente principio de lo complejo de causas y efectos en el acaecer, ha de ser tenido en cuenta en la periodización el de la inmanencia de lo artístico. El sucederse de lo histórico-general y de la literatura no resultan coincidentes; constituye un desenfoque de relieve prescindir de lo específico poético al historiar el desarrollo de la literatura.

\section{Largas duraciones y «estructuras» históricas}

El fondo más general en el que cobran sentido las obras literarias es lo histórico de «larga duración». Ya Pierre Vilar advertía hace años que el campo característico de la Historia está en los conjuntos (macro) estructurales ${ }^{27}$; ellos constituyen el «espesor» del acontecer ${ }^{28}$.

25.- Ibid., pp. 111-112.

26.- En la misma línea argumentó Juan Reglá, Introducción a la Historia, Barcelona, Teide, 1970, pp. 28-33, 36-38, 45-48.

27.- P. Vilar, "La noción de estructura en Historia», en Sentidos y usos..., pp. 97-99: p. 98. El interés por el todo de la historia es lo que en Francia - a partir de Vidal de la Blache, Lucien Febvre y Marc Bloch - se ha llamado la stntesis histórica, apoyada en estos principios: a) Hay una sola historia, pues no existen compartimentos estancos entre historia política, de las ideas...; b) La historia lo es de hechos de conjunto, no de acontecimientos individuales; c) Existe un juego recíproco entre economía, sociedad y civilización. Esta articulación constituye el problema mismo de la ciencia histórica; d) La historia es ciencia del tiempo y no del instante. Vid. Pierre Vilar, Iniciación al vocabulario del análisis histórico, Barcelona, 1980, pp, 41-42. Trasladado a lo poético, esto sería así: 1) La literatura es ciencia de forma y materia, de contenidos y formas; 2) No cabe la historia de autores u obras aisladas, sino de totalidades o conjuntos como géneros, estilos, generaciones, etc. 28.- La masa de los hechos menudos no forma «toda la realidad, todo el espesor de la historia», manifiesta Braudel (F. Braudel, La historia y las ciencias sociales, Madrid, Alianza, 1968, p. 75). 


\section{LO LITERARIO Y LA PERIODIZACIÓN LITERARIA}

La IIistoria de larga duración considera unidades cuya amplitud es secular, y que el tiempo tarda enormemente en desgastar ${ }^{29}$.

Ciertas estructuras están dotadas de tan larga vida que se convierten en elementos estables de una infinidad de generaciones: obstruyen la historia, la entorpecen y por tanto determinan su transcurrir. Otras por el contrario se desintegran más rápidamente. Pero todas ellas constituyen al mismo tiempo sostenes y obstáculos. En tanto que obstáculos se presentan como límites... de los que el hombre y sus experiencias no pueden emanciparse... También los encuadramientos mentales representan prisiones de larga duración ${ }^{30}$.

Las grandes duraciones que interesan al estudioso de las letras españolas son la Edad Media, el Antiguo Régimen (tiempos modernos) y la época contemporánea (la Burguesía). Entendemos por Antiguo Régimen la etapa histórica caracterizada por un Estado de monarquía absoluta y el orden social estamental; a grandes rasgos diremos que se corresponde con la «Edad moderna».

La época contemporánea es la de la revolución liberal-burguesa, que concluye en un Estado constitucional y orden social de clases. «Durante los tres primeros cuartos de siglo -escriben refiriéndose a nuestro XIX los especialistas-, la burguesia revolucionaria promueve toda clase de cambios con los ojos puestos en la realización de una sociedad industrializada, liberal y democrática, que se confía ha de resultar socialmente justa. Cuando estas aspiraciones se descubran incompatibles con el mantenimiento de su status la burguesia conservadora abandona los planteamientos revolucionarios de sus predecesores para adoptar soluciones cada vez más autoritarias».

Según decimos, el marco de referencia de estas largas duraciones es aquel en el que cobran sentido las materias temáticas que aparecen conformadas literariamente en las obras particulares, y por eso no ha de quedar olvidado ${ }^{31}$.

En efecto aspectos distintos del contenido de las obras literarias se explican y adquieren significación refiriéndolas a las grandes estructuras de alcance secular que configuran la historia del mundo occidental: las edades Media, Moderna y Contemporánea, feudal, nobiliaria y burguesa respectivamente. Cada una de estas etapas generales de «longue durée» puede presentar a su vez estructuras histórico-culturales sucesivas; hablamos así de sociedades renacentista o barroca, la Ilustración, etc.

¿A qué llamamos pues estructura histórica (Renacimiento, Barroco, Edad de Plata...)? Aludiremos a tratadistas como Vilar y Maravall.

Para Pierre Vilar el conocimiento histórico consiste en la investigación del vínculo entre acontecimientos y estructuras ${ }^{32}$; éstas son sistemas de dependencias, todos coherentes, conjuntos de relaciones características mantenidas durante un período suficientemente largo ${ }^{33}$. Así la sustancia de contenido de una obra poética dada debe ser vista, según el

29.- Braudel, pp. 64,70 .

30.- Ibid., pp. 70-71.

31.- Vid. la "Introducción general» de M. Artola, dir., Historia de España, I, Madrid, Alianza, 1973, pp. III-IV, que hemos tenido en cuenta y de donde procede el párrafo transcrito. Para el «antiguo régimen» y sus productos literarios, cfr. entre otros muchos trabajos el muy amplio de Noël Salomon - ahora en español-, Lo villano en el teatro del Siglo de Oro, Madrid, Castalia, 1985.

32.- Iniciación..., p. 51.

33.- Ibid., pp. 52, 55, 61 . 


\section{FRANCISCO ABAD}

enfoque de la historia total o "síntesis histórica», como un dato o hecho particular vinculable a la estructura cultural en que ha cobrado existencia y adquiere sentido.

José Antonio Maravall por su parte llega a entender las estructuras como leyes de la historia. Por analogía con la Física, llama principio de complementariedad al de que las partes lo son en un todo - los elementos en un conjunto-, y subraya cómo la ciencia histórica trata de obtener la imagen del total de la marcha de las cosas ${ }^{34}$.

Las estructuras socio-culturales constituyen totalidades concretas en las que se hallan establecidas relaciones situacionales; sólo en las mismas se encuentra dado lo real histórico.

La estructura es la forma en que se da un determinado conjunto de hechos al historiador que los observa... Ley histórica podemos considerar... a toda fórmula en la que se condensa el significado de una estructura... Leyes históricas son, entre tantos otros ejemplos, «Barroco»... «Ilustración» ${ }^{35} \ldots$

Epocas de larga duración y dentro de ellas estructuras socio-culturales forman como períodos el marco de referencia en el que cobran sentido (los contenidos de) las obras de arte verbal. Pero además estamos acostumbrados a hacer uso del concepto de generación literaria, lo que no es sino un nuevo parcelamiento dentro de cada «estructura» histórica.

\section{El método de las generaciones}

Los períodos o estructuras históricas se articulan por la sucesión de distintas generaciones que van accediendo al poder social: «Cada quince años (escribe Julián Marías), al alcanzar el poder social una nueva generación, cambia 'el mundo' - aunque sea un poco-; se produce pues un cambio 'del mundo's 36 . En la historiografía literaria es frecuente hacer uso del concepto; así la «Edad de Plata» la consideramos constituida por las generaciones de 1868, 1883, 1898, 1914 y 1927.

Seguimos al propio J. Marías en esta síntesis esencial ${ }^{37}$. Debemos entender por generación un cuerpo social; en nuestro caso generación literaria es el grupo de escritores de edades aproximadas que, participando de la misma situación histórica, asumen lugar relevante en la vida artística ${ }^{38}$.

Las condiciones de pertenencia generacional son sobre todo las de edad aproximada y algún contacto vital ${ }^{39}$; según ellas sus miembros reaccionan ante la misma realidad, y al hacerlo dibujan una conducta que aunque particularmente puede ser contradictoria, en el total es congruente. Los individuos 1, 2 y 3 coetáneos pueden oponerse en sus

34.- Teoría del saber histórico, Madrid, Revista de Occidente, $1967^{3}$, pp. 67, 83. Maravall indica asimismo - prudentemente-, que en Historia el principio de no-contradicción no posee validez absoluta (p. 62): deberá estarse atento pues a todas las complejidades, transiciones y matices.

35.- Ibid., pp. 188 ss.

36.- J. Marías, Literatura y generaciones, Madrid, Espasa-Calpe, 1975, p. 173. Lo mismo en El método histórico de las generaciones, Madrid, Revista de Occidente, 19674, p. 104, con atribución de la idea a Ortega.

37.- El método..., passim.

38.- Hemos parafraseado parte de la definición de Vítor Aguiar; cfr. V. M. de Aguiar e Silva, Teoria de la literatura, Madrid, Gredos, 1972, p. 252.

39.- El método..., p. 102. 


\title{
LO LITERARIO Y LA PERIODIZACIÓN LITERARIA
}

conductas, pero todas ellas en conjunto resultan - postula el método generacionalcongruentes entre sí. Una generación es un cuerpo social y por tanto en ella se encuentran las más diversas reacciones, todas resultado de una única y misma realidad que es la que tienen a la vista sus miembros ${ }^{40}$.

Julius Petersen ha concretado más las condiciones o factores formativos de una generación cifrándolos en los siguientes:

\author{
Fecha de nacimiento \\ Elementos educativos \\ Comunidad personal \\ Experiencias de la generación \\ El guía \\ Lenguaje de la generación \\ Anquilosamiento de la vieja generación ${ }^{41}$.
}

Configurado pues un cuerpo o grupo generacional debemos preguntarnos por su vigencia. Si consideramos cada biografía articulada por cinco períodos de quince años, las dos etapas primeras son las de niñez y juventud, y la última la de vejez. De los treinta a los cuarenta y cinco años el hombre comienza a actuar e intenta modificar el mundo que ha recibido; entre los cuarenta y cinco y los sesenta se halla en el poder, en su época de gestión. «La actuación plenamente histórica de los hombres - lo expresa así Maríasdura treinta años; pero este plazo se divide en dos fases de signo distinto y aun opuesto; quince años de gestación, quince de gestión. De los treinta a los cuarenta y cinco se lucha por imponer una cierta estructura del mundo; a los cuarenta y cinco aproximadamente se triunfa y se 'está en el poder', hasta que quince años más tarde una nueva generación ascendente impone su innovación» ${ }^{42}$. Por eso cada quince años, con el acceso al poder social de un grupo generacional, cambia algo el mundo. Coincidiendo con esto Escarpit señala que no viene a aparecer una nueva generación de escritores hasta que la anterior no ha franqueado el umbral de los cuarenta años, y la presión de estos autores consagrados cede a la de los nuevos ${ }^{43}$.

Finalmente diremos que los cálculos para el establecimiento de una serie generacional deberán hacerse de modo hipotético, corriendo si es preciso toda la serie - tras el estudio analítico - hasta que la articulación de las fechas coincida con la histórica efectiva, y que deben distinguirse las generaciones cumulativas (homogéneas con las precedentes) y las polémicas (innovadoras) ${ }^{44}$.

40.- «Algo es vigente - escribe Marías - cuando me es impuesto y tengo que contar con ello, quiera o no; pero que algo sea vigente no quiere decir que forzosamente sea aceptado. Se me imponen las vigencias, pero no me es impuesta una reacción frente a ellas. De ahí que no pueda inferirse que los hombres sometidos al mismo sistema de vigencias tengan que parecerse entre sí; sólo en una cosa: que sus reacciones - que pueden ser distintas y aun opuestas - son reacciones a una misma realidad" (Ibid., p. 97).

41.- Ibid., p. 125; G. Díaz-Plaja, Modernismo frente a Noventa y Ocho, Madrid, Espasa-Calpe, 1979, pp. 110-112.

42.- El método..., p. 107.

43.- Robert Escarpit, Sociología de la literatura, Buenos Aires, 1962, p. 52.

44.- El método..., pp. 157-159, 100. 


\section{FR.ANCISCO ABAD}

\section{Estilos y géneros}

Las etapas generales del acontecer histórico así como las «estructuras» o épocas histórico-culturales, constituyen cuadros de referencia según los cuales es posible poner en claro la significación de las obras. Ahora bien, en primera instancia compete al estudioso referirse a la literariedad o poeticidad de las mismas y no a su contenido. Toda obra artística no puede ser tomada sólo como mero documento; posee una constitución cstética que deberá analizarse. De ahí que haya que referirla al marco de la propia serie artísticoliteraria.

Surgen así los conceptos (conceptos históricos) de estilo y de género como cuadros globales convergentemente aclaratorios. En realidad la propia denominación de los principales estilos da su nombre a las épocas o estructuras socio-históricas (Renacimiento, Barroco, etc.), pero la correspondencia no es unívoca. A estos dos períodos hay que adscribir también el Manierismo; la época «romántica» es la de la «burguesía revolucionaria»; la «Edad de Plata» comprende - por ejemplo- «generación del 98» y "generación del 27", y se corresponde históricamente con el tiempo de la burguesía conservadora; ...

En todo caso importa tener presentes como marcos iniciales aclaradores los del género literario en que se inscribe el proyecto del autor al escribir y del estilo artístico. A su vez el estilo artístico general (Barroco) puede tener distintas manifestaciones como gongorismo u «oscuridad» y conceptismo o dificultad, etc.

Los estilos pueden quedar definidos en tanto sistemas de convenciones literarias o de sistemas de signos que desarrollan sus posibilidades de significación 45; además deberá atenderse a las convergencias que puedan mostrar con las demás artes, pero cuidando de no caer en analogías abusivas.

Las obras pues se explican primariamente por los datos de la serie artística, aunque en definitiva no sólo por ellos. El género literario y el estilo suponen otras tantas constricciones u hormas sobre las que el autor va tejiendo su textura poética; el Buscón - pongamos por caso-, resulta así una novela picaresca y una obra barroca; Aire Nuestro un «libro» (género simbolista) de vanguardia.

Sintetizamos el planteamiento anterior. Lo histórico es un continuo de evolución lenta o tardígrada, pero permanente; existen además distintos ritmos en esa evolución. Hay sistemas que permanecen por siglos, y que coinciden con las grandes etapas del mundo occidental: Edad Media, Moderna y Contemporánea. A su vez cada una de estas edades o etapas comprende épocas coherentes que constituyen estructuras histórico-culturales definibles (el Renacimiento por ejemplo, o la «Burguesía conservadora»). Esas grandes etapas, y sobre todo estas épocas o estructuras, constituyen el marco de referencia en el que cobran sentido - por su fondo de ideas - las creaciones literarias particulares. Pero el sentido artístico habrá de ser indagado a la luz de los sistemas de

45.- Cfr. René Wellek-Austin Warren, Teoria literaria, Madrid, Gredos, 19744, p. 318; Aguiar, Teoria..., p. 247. 


\section{LO LITERARIO Y LA PERIODIZACIÓN LITERARIA}

convención y constricción en que consisten los estilos y los géneros. Un autor escribe en el marco de un género y de un estilo; sigue las convenciones existentes o se opone a ellas 46 .

46.- En este segundo capitulillo del presente trabajo hemos transcrito a la letra una parte del guión de clase que para el problema de la periodización redactamos y usamos en la Universidad de Málaga, en el curso académico (1980-1981) en el que ocupamos allí la cátedra de «Lingǘstica general y Crítica literaria». Creemos que en nuestras páginas se da repaso a algunos conceptos de los que es útil disponer como bagaje previo a un estudio concreto.

Ahora Julián Marias ha ensayado referirse a Cervantes poniendo en conexión tanto «La España de Felipe II y la de Felipe III» como «El desenlace histórico del mundo cervantino», «Las generaciones de la España cervantína», «Las trayectorias de Cervantes», etc.: J. Marías, Cervantes clave española, Madrid, Alianza, 1990; el autor mantiene en tanto idea de fondo: «Cervantes escribe el libro [el Quijote] muy principalmente para reabsorber la integridad de su circunstancia, es el libro en el cual posee y da transparencia a su vida... No su biografía, lo que se cuenta es la de Don Quijote... no es su biografía, es su vida... El Quijote es ante todo un mundo al cual puede uno irse a vivir, y por eso es esencial que sea un libro extenso" (pp. 194-198). Pese a algunos planteamientos sugerentes, lo que han establecido la historiografía y la crítica literaria más nuestro propio análisis hacen que no siempre podamos coincidir con el presente libro; nosotros creemos (por poner un ejemplo) que las generaciones literarias del Barroco español son respectivamente las de Mateo Alemán y Cervantes; Lope y Góngora; Tirso, Quevedo y Villamediana; y Calderón y Gracián, que nacieron entre 1546$1560,1561-1575,1576-1590$ y $1591-1605$. Etc. 